\title{
Trilogy of Intellect as a New Method of Children Intellectual Development
}

\author{
Yuriy Rotenfeld \\ Luhansk National Agrarian University
}

\begin{abstract}
The new method of intellectual development among children being investigated represents a trilogy of mind, whose main thinking operation is the logical operation of comparison. The method was created due to Aristotle's understanding of philosophy as "the science about the first reasons and origins" of cognition — types of opposition which should be the beginning of the surrounding world's cognition at school. As they were discovered and set in a natural line of comparative notions, the main Plato's plan was fulfilled to reduce all particular laws to the general and to withdraw all particular laws from the general one (Plato 1993). As a result, we are talking about the building of stepwise transmission from one general notion to another more general notion that identifies the diversity of natural and social differences. As a result, it turned out to be possible to divide the whole thinking process into three related logical parts, each of which is determined by the advantageous usage of three types of cognitive means: (1) Reasonable thinking is the thinking with the help of classification notions on the basis of relations of "abstract identity" and "abstract difference”, which determine the law of noncontradiction: either A, or not A; (2) Mental concrete-general metaphysical thinking is the thinking with the help of classification, quantitative, and comparative notions on the basis of the relation of "corresponding" and variety of mathematical and physical abstractions of different complexity being studied at school; and (3) Mental concrete-general dialectical thinking is the thinking with the help of classification and comparative notions on the basis of relation of "opposition" which allows to cognize natural and social processes. In addition to the generally accepted study of reasonable and mental thinking among schoolchildren with the help of concrete sciences, the new philosophical method is an effective means of advanced development of mental thinking among children, which makes for the holistic perception of the surrounding world by schoolchildren.
\end{abstract}

Keywords: philosophy for children, intellect, reason, mind, trilogy of intellect

\section{Do Children Really Need Philosophy?}

In the middle of 1979s of the last century, the idea appeared to reconsider the educational process at school in order to change completely the thinking of people while starting to develop it from early childhood. The initiators were the scientists of Children Philosophy Development Institute (New Jersey, USA) managed by the professor of philosophy M. Lipman who offered to teach schoolchildren philosophy from kindergarten to the twelfth grade (Lipman 1991, 7-25).

According to the ideas of the followers of philosophical approach to the educational process, it helps to

Yuriy Rotenfeld, Dr., Prof., Department of Political Science and Sociology, Lugansk National Agrarian University, Ukraine; main research fields: Thinking: Demarcation of Reason and the Two Forms of Intelligence, Integration of Sciences and the Humanities Cultures, Philosophy for Children: Integration of Education and Formation of Rational Thinking of Students, History of philosophy, and Social Philosophy. Email: rotenfeld@mail.ru. 
develop the global thinking of the growing generation, helps to learn general laws of society development, realize humanization of the whole educational system.

However, there is a doubt in the sphere of philosophical approach opponents that if we should add a new subject to the educational plan of school; therefore, there are still discussions among philosophers and teachers.

One dangerous illusion is the belief that "philosophy for children" will be able to teach schoolchildren at the lessons how to think differently. We need to agree with those opponents of philosophical approach to school education who think that in order to develop critical and reasonable thinking among schoolchildren, there is no need to add a special course of philosophy. Moreover, the existing practice of children philosophy that helps them to develop their own opinion about the attitude to serious issues, can only do harm to children who identify empty words and eloquence with wisdom.

The acceptance of this thesis sets the task for adult philosophers: to find and use such methodology that could develop not only reason with its pluralism of opinions but also other thinking skills that determine the mind of a child, directed at the cognition of objective causative-relative natural and social connections. Children must know clearly where the boundary of reason is, in which frames they can easily show initiative and inventiveness and where is "the dictatorship of mind."

\section{What Is the Difference Between Reason and Mind?}

Nowadays reason and mind are grasped as connected sides of intellect, as two kinds of human thinking activity, which connection is grasped differently in different philosophical studies. But the development of not only philosophy but also other sciences needs their definite essence, to reveal their similarity and difference between them.

In such a way, the reasonable thinking is limited with frames of classification notions of usual spoken language, which includes philosophical categories, directed at the understanding of quality diversity of the world. It is determined by the law of non-opposition and is set in the frames of principle, determined by Aristotle (1975, 384-322) as "the most reliable among all origins." Aristotle formed three basic laws of formal logic that represent the core of reasonable thinking. The same laws are at the same time logic basis of the whole science. Moreover, the logic sequence and non-contradiction, that are offered to be taught at school by all existing school programs of philosophy, is just the necessary but not sufficient condition of achieving the knowledge.

The mental thinking is directed at the cognition of sequence, harmony, symmetry of the universe, revealing of causative-effective connections that reveal its essence of reality, its numeral and structural diversity that have compulsory character.

Therefore, there is no doubt that cognition is tightly connected with the abilities of our mind to use the operation of "comparison.” We can mention the words of one wonderful French philosopher C. Gelvetsiy (1715 -1771) who wrote in his composition "About the intellect": "we are able to notice the similarity and difference, correspondence and non-correspondence of different subjects and these are all operations of our intellect.” And further "... intellect, consequently, exists in order to compare our feelings and our ideas, i.e., to notice the similarity and difference, correspondence and non-correspondence between them” (C. Gelvetsiy 1973, 150 -151).

Our compatriot, the founder of pedagogical science K. Ushynskiy (1824-1870), the same way as Gelvetsiy believed that the operation of comparison was the basis of cognition, as "we cognize every subject when we compare it with another one.”

Therefore, we will pay the major attention to the succession of such an operation as "comparison" that 
allows us to determine the ways of moving from reason to mind, and its endless gradual rising from one concrete step to another that does not exist in any of school programs.

\section{Trilogy of Intellect}

There was a belief in ancient times that the cognition is tightly connected with the operation of "comparison" that allows to reveal the initial origins of being, which were called "oppositions." Therefore, the ancient Greek philosophy, created not as a separate scientific discipline, which grasps the world as the struggle between connected oppositions, arouses the major interest.

Aristotle systematizes different content of this notion from predecessors and shows wisdom as the science about the first reasons and origins of being, which started the cognition of the surrounding world; therefore, the contemporary school education must start with it as well. These are four kinds of opposition: "contradictory," “corresponding," and "surplus and possession” (Aristotle 1975, 121-168).

Each of these notions-logos reflects the reality out of dependence on its natural and social determining. Moreover, two kinds of opposition- “corresponding" and "surplus and possession" represent two different forms of the same relation. In such a way, "corresponding" combines two notions: "bigger" and "smaller", whereas the "smaller" can change from any given value to zero. That means that such notion as "corresponding" can degenerate into such notion as "privation and possession" as its extreme case.

In such a way, Aristotle means not four but three oppositions- “contradictory," "corresponding," and "opposite" that can be presented at the Fig. 1, where the notions of "Identical" and "Different" are divided into two separate sides of the scheme and determine "contradictory" —one of three kinds of Aristotle’s opposition.

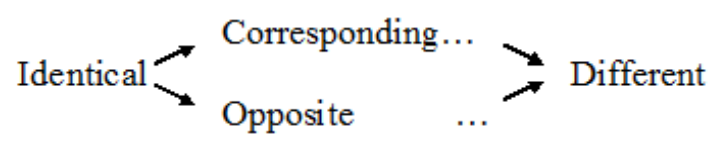

Fig. 1 Aristotle's Paradigm of Cognition in Our Interpretation.

While supplementing this scheme with new categories that reveal causative-effective connections, which are common for natural and social world, we get the universal paradigm of cognition (meta paradigm) that clearly reveals the essence of reasonable and mental thinking, their similarity and difference, their natural relationship in the frames of the unity of formal logic, logic of concrete sciences, and dialectical logic as a concrete-overall method of cognition.

Likewise the variety of numbers in arithmetic's or notes in music, we build up the comparative notions in two parallel lines and as far as we cognize the surrounding reality, we add new notions; each of them gives objective point of view about the natural and social world. Moreover, all comparative notions line up in such a way, and each less complicated notion represents the specific case (degenerated condition) of more complicated notion. For instance, "Corresponding" and "Opposite" are degenerated condition of such notions as "Orthogonal 1" and "Orthogonal 2". And such notion as "Identical" is degenerated condition of "Corresponding” and "Opposite."

The dots at the scheme (see Fig. 2) represent other not shown comparative notions.

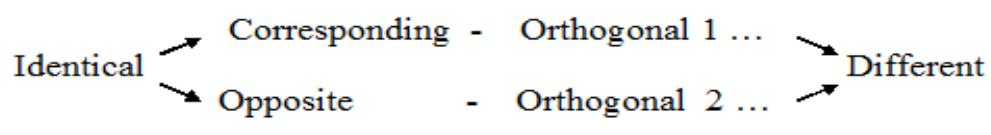

Fig. 2 Universal Paradigm of Cognition. 
Like at the stairs we will rise from the cognition of subjects' identity to the understanding of their further relations and therefore- to the understanding of more complete theoretical models that reflect harmony and sense of the universe.

The upper line of the universal paradigm of cognition through the notion of "corresponding" allows to understand the numeral diversity of the world as in order to cognize "the most" we can take "the least as the unit of measure (statics-metaphysics). The lower line through the notion "opposite" gives possibility to cognize natural and social processes (dynamics—dialectics).

Moreover, the notions of upper and lower lines reflect mental thinking, which means two same kinds: concrete-scientific mental thinking and concrete-scientific dialectical mental thinking. As a result the whole thinking may be divided into three connected logic parts; each is determined by the use of three types of notional means:

(1) Reasonable thinking is the thinking with the help of classification notions on the basis of relations "abstract identity" and "abstract difference" that determine the law of non-contradiction: either A, or not A;

(2) Mental concrete-general metaphysical thinking is the thinking with the help of classification, numeral and comparative notions on the basis of relations "corresponding" and other notions of the upper line that follow it and the large number of mathematical and physical abstractions of different complexity that are taught at school;

(3) Mental concrete general dialectical thinking is the thinking with the help of classification and comparative notions on the basis of relations "opposite" and other notions that follow it that allow us to cognize the processes in society.

According to this, the operation "comparison" is the major operation of thinking, which sets the rising moving to the whole cognition and determines the existence of some universal paradigm: trilogy of intellect (Rotenfeld 2012, 146-164) ${ }^{1}$ that is presented at the Figs. 1 and 2 and sets the totality of three logic directions that are combined with one common idea of comparison.

The first one of these directions is the formal logic, which sets the notion "contradictory" as the initial thinking paradigm. Its sides express abstract, endless difference; therefore, they are separated at the maximum distance in the universal paradigm of cognition and determine the beginning and the end of the paradigm.

The second direction is the metaphysics of concrete-scientific researches, the initial paradigm of which is the notion "corresponding."

The third direction is the dialectics of concrete-scientific philosophical researches, the initial paradigm of which is the notion "opposite," which is grasped as the surplus and lack in relation to the intermediate, i.e., in Aristotle's understanding.

Each logic is determined by its own origin, which sets the objective point of view for the cognition of reality. The reason meanwhile divides abstract differences $\mathrm{A}$ and not $\mathrm{A}$ and does not allow them to be connected in the same relation: either A, or not A. Mind, however, grabs concrete differences in unity as one side of "corresponding” or "opposite" and other comparative notions cannot exist without the other side.

Each of these three origins can be cognized in symmetrical categories (Rotenfeld 2012, 70-91) ${ }^{2}$ that characterize the successive rising of mind from one step to another and there is no possibility to skip one step. 


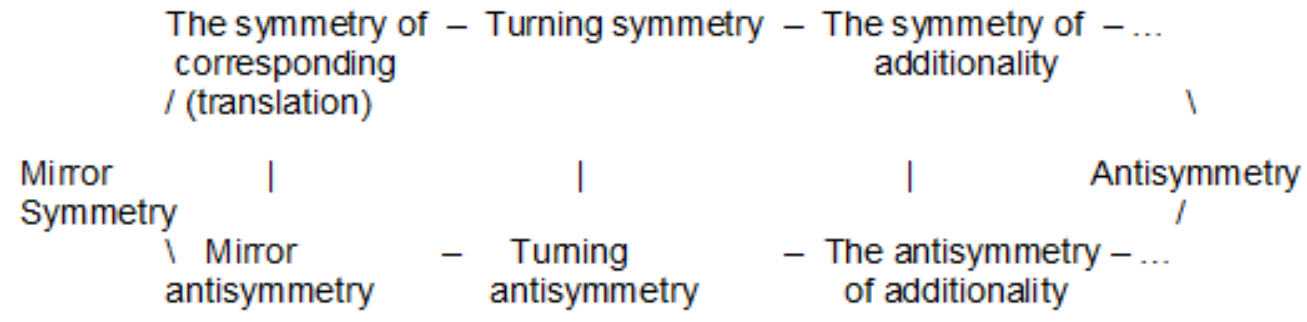

Fig. 3 Trilogy of Intellect in the Notions of Symmetry.

The categories represented at the Figs. 1, 2, and 3 bring school knowledge into a system, form complete outlook at the information that the child receives. Therefore, the aspiration to make philosophy one of the major disciplines at school deserves attention, if we grasp philosophy as "the science about first reasons and origins" as it was grasped by Aristotle.

The main in the new method is that it synthesizes natural-scientific and social-humanitarian knowledge, as long as thinking with the help of comparative notions allows us to comprehend from objective points of view not only nature but also society.

\section{Conclusion}

The system of general scientific notions represented at Figs. 1, 2, and 3 likewise natural line of numbers forms natural line of comparative notions built up one after another in a way of scientific revolution of Thomas Kuhn (Khun T. 1975).

But if numbers integrate quantitative diversity of reality, then the comparative notions integrate its structural diversity, systematize natural and social processes, and approach to the understanding of its integrity.

As the main milestones on the way to the development of concrete sciences, these notions reveal the essence of reality, and make for its mental deeper understanding. They divide the world into parts equally, reflect the correlation of the last ones correctly, and provide with objective points of view.

On the whole, the new method is the principally new pedagogical approach to school and university education.

\section{Notes}

1. Yuriy Rotenfeld. To revive the school of mind: to the history of establishment of notional thinking in sciences. The inevitability of non-lineal world: application to the magazine "Philosophic sciences": [monograph]. Moscow, "Humanitariy", (2012, 146-164).

2. Yuriy Rotenfeld. Philosophy at school: the trilogy of mind. About a new method of mental children development. Childhood as anthropological, cultural studies, psychological-pedagogical phenomenon. Samara, “As Gard”, (2012, 70-91).

\section{Works Cited}

Aristotle. Works in Four Volumes. Vol. 1. Ed. Asmus. Moscow: "Mysl”, 1975.

Gelvetsiy, C. Works in Two Volumes. Vol. 1. Ed. Momjian. Moscow: "Mysl”, 1973.

Khun T. The Structure of Scientific Revolutions. Ed. Markova. Moscow: "Progres”, 1975.

Lipman M. Thinking in Education. Cambridge: Cambridge University Press, 1991.

Plato. Works in Four Volumes. Vol. 3. Ed. Losev. Moscow: “Mysl”, 1993. 